\title{
COMUNICAÇÃO PELO OLHAR ENTRE MÃE E BEBÊ: SUBJETIVIDADE E INTEGRAÇÃO DO EU
}

COMMUNICATION BY LOOK BETWEEN MOTHER AND BABY: SUBJECTIVITY AND INTEGRATION OF SELF

\section{COMUNICACIÓN POR LA MIRADA ENTRE LA MADRE Y EL BEBÉ: SUBJETIVIDAD E INTEGRACIÓN DE YO}

\author{
Beatriz Rall Daró* \\ Henrique Abe Ogaki* \\ Maria Elizabeth Barreto Tavares dos Reis ${ }^{* * *}$ \\ Silvia Nogueira Cordeiro****
}

\begin{abstract}
RESUMO
Este artigo tem como objetivo apresentar um relato de experiência, a partir da observação de bebês baseada no método de Esther Bick. Esse método se caracteriza como um meio pelo qual a dinâmica psíquica do bebê pode ser estudada e se caracteriza por visitas semanais regulares à casa da díade mãe-bebê, com duração de uma hora, além das anotaçōes e supervisões subsequentes das observaçóes realizadas. Para se tornar sujeito, o bebê precisa passar por um processo de constituição subjetiva e integração do eu, que será auxiliado pela função materna. A comunicação pelo olhar tem importante papel nessa função, pela qual o bebê poderá se diferenciar de sua mãe e do ambiente e formar a sua subjetividade. O método Bick de observação serviu não apenas para observar elementos do funcionamento do bebê, mas também como meio de acolhimento para a díade, afigurando-se assim como um conector entre teoria e prática.
\end{abstract}

Palavras-chave: Métodos de observação. Comunicação visual. Constituição do sujeito.

\section{ABSTRACT}

This article presents an experience report based on Esther Bick's Infant Observation method. This method is a way to study psychic dynamics

Texto recebido em 29 de abril de 2014 e aprovado para publicação em $1^{\circ}$ de setembro de 2015.

Graduanda em Psicologia na Universidade Estadual de Londrina (UEL). Endereço: Rua Delaine Negro, 55, ap. 116, RB - Alto da Colina, Londrina-PR, Brasil. CEP: 86055-680. E-mail: brdim@hotmail.com.

* Graduando em Psicologia na UEL. Endereço: Rua Fernando de Noronha, 651, ap. 1002 - Centro, Londrina-PR, Brasil. CEP: 86020-905.E-mail: hike.xd@hotmail.com.

"** Doutora em Psicologia Clínica pela USP São Paulo, professora adjunta do Departamento de Psicologia e Psicanálise da UEL, psicóloga clínica. E-mail: bethtavares1@yahoo.com.br.

**** Doutora em Ciências Biomédicas pela FCM Unicamp, professora adjunta do Departamento de Psicologia e Psicanálise da UEL, psicóloga clínica. E-mail: silvianc2000@hotmail.com. 
of babies by regular weekly visits of an hour to the home of the motherinfant dyad, subsequent annotations and supervision of the observations. In order to become a subject, a baby needs to undergo a process of subjective constitution and integration of the self, which is aided by the maternal role. Visual communication is important in this function as it helps the baby to differentiate itself from the mother and the environment and form its subjectivity. The Bick method served not only to observe aspects of the functioning of the baby, but also as a host environment for the dyad, thus being a connector between theory and practice.

Keywords: Observation methods. Visual communication. Constitution of the subject.

\section{RESUMEN}

Este artículo tiene como objetivo presentar un relato de experiencia a partir de la observación de bebes, basada en el método de Esther Bick. Este método se constituye como un medio por el cual la dinámica psíquica del bebé puede ser estudiada y se caracteriza por visitas semanales regulares a la casa de la díada madre-hijo, con duración de una hora, además de las anotaciones y supervisiones posteriores a las observaciones realizadas. Para llegar a ser sujeto, el bebé tiene que someterse a un proceso de constitución e integración del yo, que será auxiliado por la función materna. La comunicación por la mirada juega un papel importante en esta función, por la que el bebé podrá diferenciarse de su madre y del medio ambiente para formar su subjetividad. El método Bick de observación sirvió no sólo para observar elementos de funcionamiento del bebé, sino también como un medio de acogida para la díada, configurándose, así, como un conector entre teoría y práctica.

Palabras clave: Método de observación. Comunicación visual. Constitución del sujeto.

\section{INTRODUÇÃO}

A partir da experiência própria dos autores com observação de bebês baseada no $\triangle$ método de Esther Bick, este artigo tem o objetivo de discutir a comunicação - pelo olhar entre o bebê e sua mãe, entendida como um importante meio de formação do vínculo entre a díade e como meio de subjetivação do sujeito.

Assim, neste trabalho, discorremos sobre o método utilizado e falamos sobre aspectos relevantes do desenvolvimento do bebê para, em seguida, tratarmos do estabelecimento da comunicação pelo olhar entre mãe e bebê, assim como sua relevância como constituinte do vínculo que se estabelece entre eles. Por fim, fazemos algumas considerações sobre o método e sua relação com a teoria apresentada. 


\section{O MÉTODO BICK DE OBSERVAÇÃO DE BEBÊS}

O procedimento utilizado neste trabalho foi adaptado do método de observação elaborado por Bick $(1964 / 1987)^{1}$ em Londres. Os autores o utilizaram num projeto de ensino vinculado à área de psicanálise numa universidade no Sul do Brasil, com o objetivo de oferecer subsídios teórico-práticos sobre a formação subjetiva do ser humano com base em conceitos da psicanálise e de capacitar o estudante para o atendimento clínico.

Esse método permite uma experiência prática de observação da formação do vínculo do recém-nascido com seu ambiente familiar e de como se estrutura seu relacionamento com seus pais e familiares (Perez-Sanchez, 1983). Ele é composto por três tempos distintos, sendo o primeiro o da observação em si, no qual o observador permanece na casa do bebê durante uma hora, em visitas semanais, mantendo uma postura respeitosa e buscando não interferir no cotidiano e no relacionamento da família. O segundo tempo é o das anotações, no qual o observador transcreve, após a visita, todos os detalhes lembrados e os sentimentos vividos durante a observação. O terceiro é o da supervisão, que ocorre com os outros membros do grupo e com um supervisor, no qual o observador relata o que foi experienciado e pode dar sentido a essa vivência (Bick, 1987; Mélega, 1997; Oliveira-Menegotto, Lopez, \& Caron, 2010).

A partir dessa experiência prática, o observador pode aprender a sentir e a direcionar seu olhar para o que aparece, conseguindo ter uma compreensão de aspectos importantes sobre a formação subjetiva de um sujeito, como a adaptação dos pais com o bebê real em relação àquilo que imaginaram sobre ele, a comunicação não verbal que se estabelece entre o bebê e sua mãe e os sentimentos despertados a partir desse contato (Oliveira-Menegotto et al., 2010).

A regularidade das observações, que ocorrem no mesmo dia da semana, no mesmo horário e com tempo regular de uma hora, demarca um setting constante. O observador parte do princípio do "não saber", de forma que não se busca nenhuma conclusão e não há interferência, como dar conselhos ou informações. Assim como na clínica, o observador deve ter uma atenção flutuante e manter-se aberto para os conteúdos que emergem na observação. Dessa forma, a experiência oferece uma oportunidade de treinamento para a atividade clínica, e a supervisão ajuda a refletir sobre o próprio desempenho (Oliveira-Menegotto et al., 2010).

Cada autor deste trabalho realizou observação com um bebê e sua respectiva família, sendo que serão apresentadas as vivências de duas experiências distintas, enfocando-se a questão referente à comunicação pelo olhar, tema deste trabalho.

A primeira data indica o ano de publicação original da obra e a segunda data indica a edição consultada pelo autor; que só será pontuada na primeira citação da obra no texto. Nas seguintes será registrada apenas a data de publicação original. 


\section{CONSTITUIÇÃO SUBJETIVA: DA PRÉ-HISTÓRIA DO BEBÊ AOS PRIMÓRDIOS DO NASCIMENTO}

Mesmo antes do nascimento, a criança já existe no imaginário dos pais. A história do bebê se inicia com o projeto da gravidez, desenvolvido pelos pais de forma consciente ou não, o que vai dando significado a essa gravidez. Todo o desenrolar dessa história até o nascimento vai fazer parte da constituição subjetiva da criança (Szejer \& Stewart, 1997).

Quando o bebê nasce, é recebido por um banho de linguagem, que são os dizeres que antecedem seu nascimento, mas que se remetem a ele. $\mathrm{O}$ banho de linguagem é composto pela pré-história do nascimento e pelas expectativas que os pais criam em torno desse bebê (Szejer \& Stewart, 1997). Isso nos leva a pensar que o sujeito já inicia seu processo de subjetivação antes mesmo de nascer, ou seja, a criança já existe no imaginário dos pais, o que pode se constituir como um protótipo do que virá a ser a subjetividade do sujeito.

Situações como essa podem ser observadas quando acompanhamos gestantes e ouvimos comentários do tipo "ele se mexe bastante, vai ser bem agitado", "espero que ela seja calma como o irmão" ou "quero que minha filha seja bailarina como eu”. Essas falas são representações do que está no imaginário dos pais e vão constituindo um lugar para esse bebê.

Esses aspectos vão determinando a forma como os pais olham para esse bebê e qual o lugar subjetivo que ele vai ocupar dentro da família. Com o nascimento, pais e bebê passarão por um período de reconhecimento mútuo e todas as expectativas criadas sobre o bebê deverão ser readaptadas à realidade. Quer dizer, a partir do nascimento do filho, os pais precisam confrontar o bebê imaginário com o bebê real (Piccinini, Gomes, Moreira, \& Lopes, 2004). Assim, os pais terão de recriar seu olhar para alguém que ainda precisa ser conhecido.

O ato do nascimento, de acordo com Freud (1910b/1996), é o primeiro dos perigos da vida, sendo a fonte original do afeto de angústia. Essa angústia do nascimento ocorre devido ao aumento da estimulação sobre o bebê, que passa a estar separado e sem a proteção do corpo da mãe, com o qual podia contar até então. Assim, logo após o nascimento, o bebê não consegue distinguir um limite entre seu eu e o mundo externo, representado, em um primeiro momento, pela figura materna, ou seja, a mãe não é vista como um objeto externo ao bebê, mas como parte de si mesmo (Cabas,1982). Isso significa que constituir uma representação do próprio corpo é parte essencial do processo subjetivo, uma vez que o corpo dá contorno e integra o eu, pois, segundo Freud, "O ego é, primeiro e acima de tudo, um ego corporal" (1996d, p. 39). 
Nas observações realizadas, foi possível constatar momentos da interação mãebebê que podem exemplificar como vai se constituindo a representação do corpo a partir dessa relação, como na hora do banho, em que a mãe passava a mão pelo corpo de sua filha enquanto conversava com ela e descrevia as partes de seu corpo: “Ah, esse é o seu pezinho!". Esse ato de expressão do afeto vai tornando o corpo erotizado, torna a relação prazerosa e, ao mesmo tempo, estreita o vínculo entre a dupla.

Essas vivências de comunicação entre o bebê e sua mãe, de ser acariciado ou contido e, como fala Jerusalinsky (2006), de ser reconhecido por ela como sujeito e receber um lugar como tal, ajudam o bebê a fazer a diferenciação entre eu e não eu e a constituir sua subjetividade.

Assim como o bebê vivencia o corpo como partes cindidas, as sensações de conforto ou desconforto são sentidas em regiôes corporais, sem ligação entre elas. Para que essas sensações se integrem e o corpo possa ser vivenciado como um, é necessária a constituição de uma imagem corporal, que se organiza pelo olhar do outro, a mãe ou alguém que faça a função materna (Cabas, 1982).

A captação da imagem especular somente se dá em sua plenitude quando essa imagem é investida pelo outro e o sujeito só se institui enquanto tal após viver a experiência da apreensão narcísica dessa imagem desejada pelo outro (Lacan, 1966/1998).

Em uma das observações, quando o bebê estava com cerca de três meses, a observadora teve a impressão de ser realmente vista pelo bebê, diferentemente das outras vezes, em que o bebê apenas olhava em sua direção, mas não demonstrava reconhecê-la. É como se, naquele momento, os olhares se cruzassem e houvesse um reconhecimento mútuo. Esses reconhecimentos pelo olhar auxiliam o bebê na diferenciação entre eu e não eu. $O$ bebê parecia perceber a importância de si mesmo no olhar da observadora, lembrando aqui as palavras de Winnicott (1975, p. 157): "Quando olho, sou visto; logo existo".

Esse processo de diferenciação entre eu e não eu também ocorre a partir da introdução da criança na linguagem pela mãe. Ao colocar palavras naquilo que a criança vivencia, a mãe produz um sentido, pois ela não apenas nomeia aquilo que é como faz uma discriminação daquilo que não é. Assim, ao nomear o bebê e a si mesma, a mãe demarca uma diferenciação entre ambos (Cabas, 1982). Isso ocorre quando a mãe diz coisas como "Você tá sorrindo pra mamãe?", "Meu bebê tá chorando porque tá com fome?" ou "Quem é o bebezinho da mamãe?".

Diante do exposto, podemos entender que tanto o olhar quanto a expressão verbal são componentes muito importantes da comunicação mãe-bebê e 
contribuem em grande parte para o processo de subjetivação deste. É o olhar materno que devolve para a criança sua própria imagem e permite que ela desenvolva uma percepção de si mesma como um sujeito inteiro (Winnicott, 1975,).

\section{A COMUNICAÇÃO PELO OLHAR: UMA VIA PARA A SUBJETIVAÇÃO}

Há muito se fala sobre a capacidade visual do bebê. Alguns estudos realizados nas décadas de 1960 e 1970 mostraram que, a partir dos 4 dias de vida, 95\% dos bebês já conseguem perceber um objeto de cor viva; aos 4 meses, já têm as mesmas capacidades visuais do adulto e também apresentam alta acuidade no reconhecimento e distinção de rostos (Greenman, 1963; Haynes White \& Held, 1965; Fagan, 1976).

Estudos mais recentes, como o de Costa, Oliveira, Bergamasco, e Ventura (2006), apontam para um desenvolvimento mais demorado de algumas das capacidades visuais do bebê. A acuidade visual, por exemplo, somente se igualaria a do adulto ao fim do primeiro ano de vida. Essa divergência de resultados pode ser em razão de diferenças metodológicas, como os próprios autores discutem no artigo. Por outro lado, os estudos de Mendes (2007) e Belini e Fernandes (2010) corroboram as pesquisas anteriores quanto ao reconhecimento de rostos, mostrando que, já nos primeiros dias de vida, o bebê apresenta interesse por esquemas faciais e por estabelecer contato ocular.

Essa acuidade proeminente dos bebês para o reconhecimento de rostos humanos parece ter uma função evolutiva e de sobrevivência física, constituindose num meio para o bebê discriminar e apresentar interesse no seu cuidador, inspirando cuidados neste (Mendes, 2007). Segundo Jerusalinsky (2006), o contato visual também está relacionado a questôes de sobrevivência psíquica, como um meio de comunicação, de identificação e de formação do sentido de eu.

Os olhos têm como função apreender o mundo externo, mas não apenas isso. Eles servem também para perceber os encantos dos objetos que são escolhidos como objetos de amor. Isso ocorre em razão de as pulsões se utilizarem dos mesmos órgãos e sistemas corporais que servem à sobrevivência, de modo que o ato de ver se compóe de processos tanto conscientes quanto inconscientes (Freud, 1996a).

A função do olhar, dessa forma, é uma pulsão que Freud (1996c) denominou de pulsão escópica e que envolve tanto olhar quanto ser olhado. Sabemos que, 
para o autor, a pulsão é o fenômeno psíquico que ocorre no limite entre a psique e o soma; seria algo como a representação do instinto na mente. A pulsão, além disso, caracteriza-se como uma força que exerce pressão constante, cuja finalidade é a sua satisfação por meio do encontro com o objeto.

Nessa perspectiva, olhar e ser olhado é, então, pulsional. O objeto é aquilo que é visto ou o perceber estar sendo visto, respectivamente. Primeiro há a visão de objetos externos e, em seguida, a percepção da visão do outro sobre si mesmo. A satisfação decorrente desse ato está relacionada à libido, como uma forma de troca, em que a libido é dirigida para o outro e, também, recebida pelo outro.

Algo relacionado a isso pôde ser percebido em uma das observações, em que o bebê sorria quando encontrava o rosto da mãe e buscava o seu rosto quando ela se afastava, chegando a virar a cabeça e esticar o corpo na tentativa de revê-la, demonstrando o que pode ser entendido como uma forma de prazer e conforto por encontrar novamente o rosto de sua mãe. Outro exemplo disso seriam as brincadeiras nas quais se cobre o rosto da mãe ou do bebê, em que é possível perceber na expressão do bebê o prazer de reencontrar o objeto de satisfação, o rosto da mãe.

A comunicação pelo olhar é um dos principais meios de interação entre a mãe e o seu bebê. Essa forma de comunicação não verbal manterá sua importância por toda a vida do sujeito (Lebovici, 1987). Neste sentido é que pensamos a comunicação visual entre mãe e bebê como um importante elemento formador do vínculo da dupla, embora não exclusivo. Levando em consideração que o olhar é uma forma de comunicação não verbal e uma via de troca de libido entre o bebê e sua mãe, então podemos entender a sua importância, desde os primeiros dias de vida, para a constituição subjetiva do sujeito. É a partir desse investimento que a mãe demonstra supor um sujeito no corpo do bebê, olhando para além daquilo que se dá a ver pelos seus comportamentos, o que permite a constituição psíquica dessa criança (Jacintho, 2012).

Reconhecer e distinguir o rosto da mãe permite que o bebê se identifique com ela e, em grande parte, essa identificação se dá por meio do olhar (Cabas, 1982). A identificação parece ser o pano de fundo para a formação do vínculo entre a díade.

Os autores deste trabalho, por meio do método Bick, puderam observar algo referente a esse reconhecimento da mãe e do começo do estranhamento de outras pessoas. Um exemplo, já mencionado, foi quando um dos bebês começou a sorrir assim que via a mãe e seguia seu rosto com os olhos, não fazendo o mesmo com outras pessoas, como a irmã mais velha, que brincava com o bebê e tentava fazê-lo sorrir, porém sem êxito. Outro exemplo foi a fala de uma das mães de que 
o bebê havia começado a estranhar pessoas desconhecidas e chorava caso fosse segurada no colo por um estranho, embora gostasse de permanecer no colo.

Em outra observação, o bebê, no colo da mãe, olhava-a fixamente, de uma maneira séria. Em seguida, sua avó, que estava presente no dia, comentou que era a primeira vez que a mãe deixava os cabelos soltos na frente da filha. Podemos pensar que, naquele dia, o bebê não estava conseguindo reconhecer sua mãe, que aparecia para ela de forma diferente, como se fosse outra pessoa.

A função do olhar, além de fazer parte das pulsões, está estreitamente relacionada ao espelho (Zimerman, 1999). Esse tema é trabalhado por diferentes autores, como Lacan e Winnicott.

De acordo com Winnicott (1975,), quando o bebê olha o rosto da mãe, o que ele vê é a si mesmo. Em outras palavras, olhar o rosto da mãe e perceber o olhar dela sobre si ajuda o bebê a fazer o contorno de seu eu. O rosto da mãe, assim, funcionaria como um espelho que reflete para o bebê quem ele é. Nesse sentido, o autor coloca que há consequências caso o bebê não receba de volta esse seu olhar pela mãe, ocorrendo o atrofiamento da capacidade criativa e a interrupção da espontaneidade. $O$ fato de o bebê olhar para a mãe e não se ver refletido em seu rosto faz com que ele afaste suas próprias necessidades pessoais para se defender, de forma que não ocorre a comunicação entre os olhares.

A partir dessa concepção de espelho de Winnicott (1975), percebemos que a mãe exerce com seu filho justamente uma função de integração do eu e de subjetivação do bebê. E isso é feito em parte através do seu olhar, que, em outras palavras, é um investimento de libido. Ao devolver o olhar, como um espelho, a mãe reconhece o bebê como pessoa e permite que ali se desenvolva um sujeito.

Seewald (1999) complementa a teoria do espelho winnicottiana, afirmando que o rosto da mãe reflete para o bebê o projeto imaginário que ela havia reservado para ele antes do nascimento ou mesmo antes da gravidez. $\mathrm{O}$ projeto imaginário refletido no rosto materno é, em si, parte do processo de construção subjetiva da criança.

Outra concepção sobre o espelho é apresentada por Lacan (1998), a qual antecede a de Winnicott. Sua teoria do estádio do espelho trata de um marco significativo no desenvolvimento infantil. É nesse ponto, entre os 6 e 18 meses de vida, que a criança, ao mirar o espelho, pode compreender que o reflexo que vê é ela mesma. O espelho integra o corpo infantil, até então percebido pela própria criança de forma fragmentada.

Para o autor, o estádio do espelho consiste em três tempos: no primeiro, há uma confusão quanto àquela imagem e um impulso no sentido de se apoderar 
dela (é comum, nesse momento, que a criança investigue o que há por trás do espelho); no segundo, a criança já compreende que o que ela vê no espelho é apenas uma imagem e não um outro real; mas somente no terceiro tempo é que ela é capaz de identificar que aquela imagem se refere a ela própria. Mas é preciso destacar um detalhe importante nesse processo: a criança só pode perceber-se no espelho com a condição de que um adulto lhe diga que é ela mesma refletida (Lacan, 1998).

A passagem pelo estádio do espelho, de modo simbólico, é uma das condições para a compreensão da existência tanto de si quanto do outro. O espelho, na teoria lacaniana, tem função de integração corporal e, portanto, do eu.

Entretanto, como Lacan (1998) já havia destacado, o olhar está atrelado à linguagem, sendo esta uma condição para a função do olhar ou espelho ser efetiva. O conceito de imagem inconsciente do corpo, de Dolto (2012), ajuda a compreender o entrelaçamento da linguagem e do olhar entre si e dessas funções com o corpo. Segundo essa concepção, haveria um tempo em que o corpo tem uma função representativa, que é anterior mesmo ao estádio do espelho, como proposto por Lacan. Nesse tempo, por meio da fala, dos afetos e da vivência corporal e relacional, o corpo é marcado por impressóes somatopsíquicas, a partir das quais se formam as primeiras referências da imagem corporal e subjetiva. Para a autora, a linguagem faz a amarração entre a imagem do corpo (que é inconsciente) e o esquema corporal (pré-consciente ou consciente), e é durante o estádio do espelho que se realiza o recalque da imagem inconsciente do corpo em nome de uma corporeidade visível. Portanto se pode compreender que a linguagem liga as sensações, experiências e vivências corporais, assim estabelece uma ponte entre o bebê, que ainda não possui um corpo integrado, com o outro, o diferente de si.

Segundo Dolto (2012), a imagem do corpo é a síntese viva de nossas experiências emocionais, inter-humanas, repetitivamente vividas através das sensaçôes erógenas primitivas ou atuais. Todo o contato com o outro é subtendido pela imagem do corpo; é na imagem do corpo, suporte do narcisismo, que o tempo se cruza com o espaço e que o passado inconsciente ressoa na relação do presente.

De todo modo, cabe lembrar também que tanto o olhar quanto a linguagem tratam de diferentes formas de comunicação, pois, caso contrário, tanto a criança que nasce cega quanto a que nasce surda não seriam capazes de se subjetivar e se constituir como sujeitos, o que não se verifica na prática.

Tendo isso em vista, é interessante citar estudos de crianças com cegueira congênita, ou seja, que nascem sem a capacidade de visão, como o de Santos e 
Marinho (2009), sobre como acontece o seu processo de subjetivação. Partindo do pressuposto do estádio do espelho como condição para a integração do eu e para a diferenciação do não eu, investigam como esse processo pode ser possível em bebês que não podem ver seu reflexo no espelho nem ver o olhar de suas mães sobre si.

Nesse estudo, Santos e Marinho (2009) apontam que o bebê cego encontra meios alternativos para se constituir, como o tato e a audição. Esses achados corroboram as ideias de Freiberg (1977, apud Almeida, 2008) de que o bebê cego permanece por mais tempo utilizando a boca como centro de impulsos eróticos e agressivos, além de fonte ativa de exploração externa, substituindo os olhos. Posteriormente, quando a capacidade de percepção e alcance de objetos pela criança cega foi parcialmente transferida para as mãos, o bebê pode usar as mãos como boca e as unhas como dentes. Freiberg ressalta que comportamentos geralmente considerados agressivos, tais como gestos de arranhar e beliscar, podem, na criança cega, ter o sentido de lidar com terrores desintegradores (Freiberg, 1977, apud Almeida, 2008). Essa preponderância de um órgão por outro deve-se não somente à capacidade de adaptação perceptiva, mas também à flexibilidade da libido.

Disso decorre que, para o bebê sem visão, o toque, a voz e as palavras da mãe ganham tanta importância quanto o seu olhar para bebês videntes, confirmando as proposições de Winnicott (1975,), de que a criança cega precisa utilizar de percepções advindas de outros sentidos para ver-se refletida pela mãe.

\section{DA TEORIA À PRÁTICA: UMA OBSERVAÇÃO}

Levando em consideração o que foi exposto sobre o olhar e que a prática de observação trata de um olhar para algo que acontece ali naquelas relações entre mãe e bebê, é interessante ressaltar que o próprio método Bick constituise como uma comunicação pelo olhar. Essa comunicação não ocorre somente entre mãe e filho, pois, durante a visita na casa da dupla, o observador, com a sua presença, dirige o seu olhar a eles, que são afetados por esse olhar, assim como o observador é afetado pelo olhar da mãe e do bebê. Nesse sentido, a observação parte tanto do observador quanto da mãe e de seu bebê. Disso decorre que os mais diversos tipos de sentimentos podem ser suscitados. Por exemplo, é comum a mãe se constranger diante da ideia de ser observada. Em alguns momentos, os observadores tiveram a impressão de que as mães não ficavam totalmente à vontade com sua presença e se sentiam inseguras no cuidado das filhas.

O observador também pode se constranger em ser um estranho que chega à casa, como no primeiro dia de observação, em que houve certa insegurança ao 
passar pela porta: "Como serei recebido?", "Como o bebê perceberá a minha presença?”, "O que pensarão desta atividade?". As respostas a essas e outras questôes foram obtidas pelas falas, mas principalmente pelo olhar sereno da mãe, que serviu como sinal de aceitação.

Esses exemplos são uma evidência de que, embora a função do olhar tenha enorme importância para a constituição do sujeito nos momentos iniciais de vida, esse tipo de comunicação continua a ter importância ao longo de toda a vida adulta. $\mathrm{O}$ olhar pode revelar muitos aspectos que não são falados. Por vezes, apenas pelo olhar do outro, já somos capazes de traduzir os seus sentimentos ou intençōes.

Foi possível constatar nas observações que, em alguns momentos, a mãe parecia buscar aprovação ou reprovação do observador de alguma atitude ou intenção que ela tinha em relação ao bebê. Em uma situação, a mãe comentou com o observador sua dúvida quanto ao momento de realizar o desmame ou em que momento colocar o bebê na creche.

Isso corrobora o que Jacintho (2012) mostra em seu trabalho, apoiado na prática em um espaço de acolhimento em que o olhar de um terceiro pode servir de suporte para o olhar materno, enquanto propicia um espaço de escuta e observação. Nesse trabalho, é criado um espaço de encontro e socialização para bebês, na companhia dos pais ou responsáveis, os quais também podem se encontrar com outros cuidadores e trocar experiências. Dessa forma, a instituição oferece um espaço de escuta e acolhimento para ambos, tendo o olhar de um psicanalista sobre o que ali aparece. Esse modelo de acompanhamento segue uma perspectiva psicanalítica de prevenção.

O estudo de Golin, Benetti, e Donelli (2011) em um abrigo para crianças reafirma essa abordagem preventiva com base no método Bick. As autoras utilizam o método como meio de coleta de dados e ressaltam os diversos contextos em que ele pode ser aplicado.

O trabalho realizado com o método de observação de bebês proposto por Bick pode se constituir, assim como a instituição citada por Jacintho (2012), como um olhar a mais que dá suporte para o olhar da mãe sobre seu bebê. Portanto a presença e o olhar do observador durante as visitas oferecem um acolhimento para a dupla observada.

Ainda sobre o papel de suporte que o observador desempenha, OliveiraMenegotto, Lopes e Caron (2006) afirmam que a postura receptiva e empática permite que sejam recebidas comunicações do bebê, da mãe e da família. $\mathrm{O}$ observador se torna um recipiente dos sentimentos da dupla, compartilhando o 
espaço emocional que existe entre eles. Cria-se, assim, uma situação acolhedora, que permite à mãe falar, refletir e descarregar seus sentimentos sobre seu bebê em outra pessoa.

A observação, dessa forma, pode ter uma função terapêutica, quando fornece apoio à mãe, com possibilidade de compartilhar suas vivências com alguém que escuta o que ela tem a dizer, sem procurar intervir. A mãe pode direcionar seu olhar ansioso para o observador e se aliviar desse sentimento, permitindo um olhar mais tranquilo e acolhedor para seu bebê.

Isso pôde ser percebido, por exemplo, em uma das observações na qual a mãe deu um feedback ao observador, no último encontro, de como o trabalho havia sido bom para ela, pois pôde conversar com alguém que a escutava sem fazer julgamentos, tendo uma atitude diferente das pessoas com as quais ela se relacionava no seu dia a dia. Isso possibilitou que ela se expressasse livremente e recebesse um acolhimento.

\section{CONSIDERAÇÕES FINAIS}

Diante do que foi exposto, podemos entender que a comunicação pelo olhar entre a mãe e seu bebê é de extrema importância, pois é pelo olhar que um pode reconhecer o outro e se identificar com ele, de forma a estreitar o vínculo afetivo. Também é pelo olhar que se inicia a interação, uma vez que o bebê ainda não é capaz de falar ou compreender totalmente o que é dito; é por meio da comunicação não verbal, daquilo que se dá a ver, que a dupla vai se relacionar.

A partir da visão, o bebê começa a apreender o mundo no início da vida. Além de perceber o que é externo, ele começa a reconhecer a si mesmo pelo olhar materno, que investe o filho libidinalmente e supõe um sujeito naquele corpo, permitindo que ali se expresse uma subjetividade. O bebê vai organizando e dando sentido às suas experiências com base naquilo que é devolvido pelo olhar da mãe, ou seja, ela vai mostrando para a criança quem esta é.

Considerando-se a experiência dos autores com a observação, no contexto de um projeto vinculado à universidade, entendemos a importância do método de observação de bebês inaugurado por Bick tanto como instrumento de ensino como também um instrumento terapêutico, de acolhimento para a família, e de pesquisa.

Recordamos que a experiência com esse método possibilitou uma melhor compreensão dos fenômenos estudados pela psicanálise, como também o desenvolvimento de habilidades relacionadas às capacidades de acolher, aguardar, conter e conter-se, além da própria capacidade de observar, as quais são de extrema importância e necessárias ao fazer psicanalítico. 
Portanto, a partir desta experiência, os observadores puderam presenciar, na prática, como ocorre o desenvolvimento inicial, elementos que constituem a formação subjetiva do bebê e aspectos da dinâmica familiar, tendo um entendimento melhor da teoria e podendo fazer uma articulação entre o que é visto em textos e o que é visto em campo. A supervisão das observações contribuiu nesse ponto, pois ajudou a estabelecer essa relação teórico-prática.

A observação também contribuiu para a atuação profissional, tanto para entender aspectos do início da vida, que podem vir a ajudar na compreensão de casos que apareçam na clínica, quanto com a postura profissional de ser receptivo e não interferir no processo familiar, manter o setting e estar atento àquilo que é comunicado, mesmo que de forma não verbal.

O tema da comunicação pelo olhar foi aqui destacado, tendo em vista pensarmos ser essa comunicação uma ferramenta do próprio método Bick. As experiências práticas retratadas tiveram a intenção de ilustrar elementos da teoria, por meio de um relato de experiência.

As questôes sobre a comunicação pelo olhar não se esgotam neste artigo. Muitas outras podem surgir, para as quais estudos futuros podem trazer elucidação. 


\section{REFERÊNCIAS}

Almeida, M. M. (2008). A contribuição da prática de observação de bebês para o desenvolvimento de recursos de continência no trabalho com uma criança autista cega. In: M. P. Mélega, \& M. C. Sonzogno, (Orgs.), O olhar e a escuta para compreender a primeira infância. (pp. 159-168). São Paulo: Casa do Psicólogo.

Belini, A. E. G. \& Fernandes, F. D. M. (2010, janeiro/março). Desenvolvimento do olhar e do contato ocular em lactentes de zero a quatro meses de idade. Revista Brasileira de Saúde Materno Infantil , 10(1), 85-93. Recuperado a partir de http://www.scielo.br/scielo.php?script=sci_arttext\&pid=S1519$38292010000100009 \& \operatorname{lng}=\mathrm{en} \& \mathrm{nrm}=$ iso

Bick, E. (1987). Notes on infant observation in psycho-analytic training. In: M. Harris, \& E. Bick, Collected papers of Martha Harris and Esther Bick. (pp. 240256). London: The Roland Harris Education Trust, 1987.

Cabas, A. G. (1982). Curso e discurso da obra de Jacques Lacan. São Paulo: Moraes.

Costa, M. F., Oliveira, A. G. F., Bergamasco, N. H. P. \& Ventura, D. F. (2006). Medidas psicofísicas e eletrofisiológicas da função visual do recém-nascidos: uma revisão. Psicologia USP, 17(4), 15-33. Recuperado a partir de http://www. scielo.br/pdf/pusp/v17n4/v17n4a02

Dolto, F. (1984). A imagem inconsciente do corpo. São Paulo: Perspectiva, 2012. (Originalmente publicado em 1984).

Fagan, J. F. (1976). Infants' recognition of invariant features of faces. Child development, 47(3), 627-638.

Freud, S. (1910). A concepção psicanalítica da perturbação psicogênica da visão. In J. Salomão (Trad.), Edição standard brasileira das obras psicológicas completas de Sigmund Freud (Vol. 11, pp. 219-230). Rio de Janeiro: Imago, 1996a. (Publicado originalmente em 1910).

Freud, S. (1910). Um tipo especial de escolha de objeto feita pelos homens (Contribuições à psicologia do amor I). In J. Salomão (Trad.), Edição standard brasileira das obras psicológicas completas de Sigmund Freud (Vol. 11, pp. 169182). Rio de Janeiro: Imago, 1996b. (Publicado originalmente em 1910).

Freud, S. (1915). Os instintos e suas vicissitudes. In J. Salomão (Trad.), Edição standard brasileira das obras psicológicas completas de Sigmund Freud (Vol. 14, 
pp. 117-146). Rio de Janeiro: Imago, 1996c. (Publicado originalmente em 1915).

Freud, S. (1923). O ego e o Id. In J. Salomão (Trad.), Edição standard brasileira das obras psicológicas completas de Sigmund Freud (Vol. 14, pp. 13-82). Rio de Janeiro: Imago, 1996d. (Publicado originalmente em 1923).

Golin, G., Benetti, S. P. C. \& Donelli, T. M. S. (2011, outubro-dezembro). Um estudo sobre o acolhimento precoce inspirado no método Bick. Psicologia em Estudo , 16(4), 561-569. Recuperado a partir de http://www.scielo.br/scielo. php?script=sci_arttext\&pid=S1413-73722011000400007\&lng=en\&nrm=iso

Greenman, G. W. (1963). Visual behavior of newborn infants. In: Solnit, A. \& Provence, S. (Org.). Modern perspectives in child development. (pp. 71-79). New York: International Universities Press.

Haynes, H., White, B. L. \& Held, R. (1965). Visual accommodation in human infants. Science, 148(3669), 528-530.

Jacintho, A. L. (2012). Clínica da prevenção: o olhar sobre o corpo do bebê. Estilos da Clínica: Revista sobre a Infância com Problemas , 17(2), 242-261. Recuperado a partir de http://www.revistas.usp.br/estic/article/view/49648/53751

Jerusalinsky, J. (2006). Enquanto o futuro não vem. Salvador, Belo Horizonte: Ágalma.

Lacan, J. (1966). O estádio do espelho como formador da função do eu: tal como nos é revelada na experiência clínica. In V. Ribeiro (Trad.), Escritos (pp. 96-103). Rio de Janeiro: Jorge Zahar, 1998. (Publicado originalmente em 1966).

Lebovici, S. (1987). O bebê, a mãe e o psicanalista. Porto Alegre: Artmed.

Mélega, M. P. (Org.) (1997). Observação da relação mãe-bebê: método Esther Bick. Tendências. São Paulo: Unimarco.

Mendes, A. I. F. (2007). Caricatura e reconhecimento de faces (Tese de Doutorado). Universidade de São Paulo, Programa de Pós-graduação em Psicobiologia, Ribeirão Preto. Recuperado a partir de http://www.livrosgratis.com.br/ arquivos_livros/cp044485.pdf

Oliveira-Menegotto, L. M., Lopes, R. C. S. \& Caron, N. A. (2006). O método Bick de observação da relação mãe-bebê: aspectos clínicos. Psicologia Clínica, 


$$
\text { 22(1), 39-55. }
$$

Perez-Sanchez, M. (1983). Observação de bebês: relaçôes emocionais no primeiro ano de vida. Rio de Janeiro: Paz e Terra.

Piccinini, C. A., Gomes, A. G., Moreira, L. E. \& Lopes, R. S. (2004). Expectativas e sentimentos da gestante em relação ao seu bebê. Psicologia: Teoria e Pesquisa, 20(3), 223-232. Recuperado a partir de http://www.scielo.br/pdf/ptp/v20n3/ a03v20n3

Santos, M. J. M. \& Marinho, L. A. (2009). Um corpo na escuridão: o estádio do espelho em cegos. Mosaico: estudos em Psicologia, 3(1), 1-9.

Seewald, F. (1999). Fundamentos psicanalíticos com crianças e adolescentes. In D. E. Zimerman (Org.), Fundamentos psicanalíticos. (pp. 421-435). Porto Alegre: Artmed.

Szejer, M. \& Stewart, R. (1997). Nove meses na vida da mulher: uma abordagem psicanalítica da gravidez e do nascimento. São Paulo: Casa do Psicólogo.

Winnicott, D. W. (1967). O papel de espelho da mãe e da família no desenvolvimento infantil. In W. D. Winnicott. O brincar e a realidade. (pp. 153-162). Rio de Janeiro: Imago, 1975. (Publicado originalmente em 1967).

Zimerman, D. E. (1999). Fundamentos psicanalíticos: teoria, técnica e clínica. São Paulo: Artmed. 